Article

\title{
Travel Behavior of SME Employees in Their Work Commute in Emerging Cities: A Case Study in Dhaka City, Bangladesh
}

\author{
Nuren Abedin $1, * \mathbb{C}$, Md Mahmudur Rahman ${ }^{2}$, Muhammad Ismail Hossain ${ }^{3}$, Kenji Hisazumi ${ }^{1}$ \\ and Ashir Ahmed ${ }^{1,2}$ \\ 1 Graduate School of Information Science and Electrical Engineering, Kyushu University, Fukuoka 819-0395, \\ Japan; kenji.hisazumi.741@m.kyushu-u.ac.jp (K.H.); ashir@grameen.com (A.A.) \\ 2 Global Communication Center, Grameen Communications, Dhaka 1216, Bangladesh; \\ mahmud@mail.grameen.com \\ 3 Faculty of Business Studies, University of Dhaka, Dhaka 1000, Bangladesh; muhammad.hossain@du.ac.bd \\ * Correspondence: nuren@f.ait.kyushu-u.ac.jp; Tel.: +81-92-802-3632
}

Received: 31 October 2020; Accepted: 5 December 2020; Published: 10 December 2020

check for updates

\begin{abstract}
Corporate employees like to save the time they spend commuting to work. However, public transport in many emerging cities is not scheduled. Only big enterprises can afford scheduled staff buses. Rideshare services (e.g., Uber, Lyft, Pathao) can be a good alternative but are not affordable for every individual. This study aims to design a group rideshare service as a sustainable alternative for potential employees. For that purpose, it is important to know their commuting pattern. A survey was carried out on 314 employees of 20 Small and Medium Enterprises (SMEs) working in one office complex. This paper reports their current travel pattern in terms of distance, cost, time, and mode of transportations to measure their potentiality to use a group rideshare service uniquely designed for a work commute. This paper recommends that employees living within a distance of 2.5-15 km, currently using motorized vehicle for their work commute, who can spend \$40 USD a month for work commute and agree to a mutually-determined commuting schedule are the most fitting potential users for an effective and financially sustainable rideshare service for the studied community. The same methodology can be used to obtain the potential ride share users to design a ride share model for other similar communities.
\end{abstract}

Keywords: SME employees; work commute; rideshare; emerging cities

\section{Introduction}

The demand of mobility is increasing as more people are actively engaging in economic activities in emerging cities [1]. More women, and people with disabilities and special needs are actively participating in the economic wave. Also, because of the increasing awareness among people regarding sharing resources to conserve resources, people are making changes in lifestyle like not owning a private car in favor of shared mobility services [2]. Thus, the requirements in designing and developing mobility capacity to cater to mobility needs are also changing. With easier and wider access to information through the internet, and integration of transport information on the internet, ride-sharing services have become a popular mode of urban transport around the world, including in developing countries. However, the existing services are yet to become an attractive transportation mode among office goers for their regular work commute, especially in developing countries.

Information and Communication Technology (ICT) promises to revolutionize the urban mobility [3]. Ubiquitous and faster internet has been continually leveraging the capacity development of Mobility as a Service (MaaS) with services like car-sharing, ridesharing, and ride-hailing. The ride-hailing 
service Uber gained momentum within the first 3 years after its establishment in the US and in other international markets [4]. Such services are also becoming popular in developing countries for example, "Grab" in developing Asian countries like Indonesia and Vietnam [5].

Ride sharing services have been avaliable for quite long time; however, several constraints including legal [6] and technological $[7,8]$ have not allowed such services to obtain the desired scale within and across countries. The emergence of the GPS-enabled smartphone back in 2007 and the pro-mindset of regulatory agencies significantly reduced the mentioned inhibiting factors, and has subsequently encouraged companies to start offering ride sharing services locally as well as internationally. For example, uber is operating in 65 countries and in more than 700 cities [9]. The phenomenal growth of international ride-sharing companies like Uber, Lyft, and Sidecar also encourage country specific ride-sharing companies like Didi Chuxing and Grab to start and grow locally and internationally. The widespread acceptance of these ride-sharing services was primarily due to their complementary nature toward the existing mode of urban public transportation [10]. In addition, prior research found that ride sharing services reduce traffic congestion, car ownership, emission level, and drivers' stress, and they increase consumer welfare and facilitate the concept of 'smart cities' [11,12].

The mentioned benefits of ride-hailing services have also led developing countries to approach such services with a very positive mindset [13]. Developing countries in general suffer from the absence of ideal infrastructure, including public transportation systems, so they gladly accept this idea, which consequently opens up opportunities for new companies. Local companies in these countries have seized this opportunity and, building on such opportunity, they have grown significantly and are operating internationally. For example, Pathao, a Bangladeshi ride sharing company was valued above USD 100 million in 2018 [14]. Ride-sharing services, due to their unprecedented growth, now occupy $23 \%$ of the transportation sector of Bangladesh [15]. For developing countries, ride sharing services have been shown to contribute toward social growth in the form of developing an entrepreneurial mindset [16]. This may be true for individually as well as for institutions. In particular, the digital economy and its byproducts such as ride sharing services can yield significant benefits in terms of productivity and more entrepreneurial opportunities [17] for small and medium enterprises (SMEs) of developing countries.

Our previous research [17] investigated the suitability of rideshare services for rural communities in Bangladesh. A ride share model for urban female workers was proposed in our earlier work [18]. There are still more areas to explore with specific reference to cities in developing countries in work commuting contexts. For example, employees of all organizations are not equally equipped at least financially to take advantage of the existing ride sharing services offered in the urban geographic milieu of these countries.

Rideshare services are becoming increasingly popular in Bangladesh as an alternative mode of transport for those who do not feel comfortable using a public bus or informal transport services, or who are looking for a faster, safer and more convenient ride. The existing ride-share services as offered in Bangladesh are mostly designed for the general user/customer segment and mostly serve the mobility needs of individual customers. There is hardly anything available to serve the mobility needs of corporates, especially for Small and Medium Enterprises (SMEs). Employees working at the SMEs are particularly struggling to fulfill their mobility needs as the existing ride sharing services are way beyond their reach in terms of affordability. This is particularly true when we consider ride sharing services as a regular commuting alternative for their work. SME employees are yet to be considered as a viable market segment. Thus, very little work has been done so far at academic and practitioner level relating to designing a ride-sharing service for the working community of SMEs with specific reference to their use of transport. Specifically, such work would involve designing shared ride models and turning them into entrepreneurial opportunities in developing countries. The scope for SMEs mobility is not only limited to its organization's mobility needs, but also its employees' mobility needs. It is 
thus apparent that the breath of ridesharing can be broadened such that it accommodates community mobility needs such as corporate community mobility needs.

Our research focuses on the mobility needs of the working community of SMEs in developing countries. A staff bus as a form of shared mobility has existed since many years, i.e., a big enterprise arranges a bus or vans for their own staff for their daily work commute. However, the limitation of such services is that this shared vehicle is used only within one organization. As occupying these kinds of resources is expensive, it is only possible for big enterprise to afford such services. Employees of SMEs do not usually get access to such staff bus services and have to use the existing local transport, despite the associated shortcomings of such transportation options. Hence, a new type of transport mode is required which would be affordable, safe, and appropriate for the daily work commute for the employees of SMEs in developing countries.

With an effort to design an affordable ride share model for a safer and better work commute, the travel pattern of 314 employees was studied who work in different SMEs, but commute to a common vicinity from different zones of a city. The location of our case study is the western side of Dhaka city in Bangladesh, called Mirpur. We present and discuss the travel behavior of these employees in terms of distance, cost, and time schedule of their travel. In addition, our study designs and recommends the criteria of a non-potential and potential group rideshare service for the work commute. A potential group rideshare user would be the employee who lives in a distance of 2.5-15 km, can spend \$40 USD monthly on their work commute, uses a motorized vehicle and agrees to a mutually-determined commuting schedule.

\section{Research Motivations, Objectives and Questions}

In this section, we describe our research motivations and outline the research questions.

\subsection{Public and Private Transportation Sectors of Dhaka City}

Our experiment city, Dhaka, is the 5th largest city in the world by population with 14.5 million people [19]. There are approximately 7000 public buses and minibuses to deliver the commuting needs of the city's people, and this is considered as the main mode of transport in the city. There is no commuter train service available in the city yet. The public transport in Bangladesh is loosely organized and weakly regulated [20,21]. A report by the World Bank in 2009 identified the major problems with public transport in Dhaka, which are: unsafe, poor quality vehicles, low service standards, low capacity compared to demand, on-street competition for passengers, adherence to schedules and weak fare control [22]. As a result, passengers experience a plethora of problematic outcomes like high accident rate [23], overcrowded vehicles, and lack of comfort, safety, and security [24]. Overcrowded transport restricts women and minors' use of buses during rush hours [25]. Discomfort and harassment such as verbal teasing, groping, unwanted touches, sexual abuse, etc., are often reported by female passengers of public transportation [26]. Both males and females have to experience a rough travel to work due to many intrinsic impacts like substandard/poorly maintained vehicles, noise of vehicles, waiting time, vehicle modes, transfers, cost, etc. [27].

According to a study [27] conducted in 2015 among 200 families living in Dhaka, the capital city of Bangladesh, people find public transportations unwanted and harmful to them for the reasons below:

1. It is unsafe due to untrained drivers and bus staff, numerous accidents, harassment incidents inside vehicles, theft, robbery, etc.

2. Commuting by public transport leaves the passengers exhausted and in an irritable mood when they commute using public transports and this harms their productivity at work.

3. Public transport is less cost effective as it comes with an energy cost and psychological cost along with a monetary cost. Commuters do not get a satisfactory service in return for what they pay.

However, lack of availability of alternative transport modes is forcing these 2015 study respondents to use the traditional modes of transport, even if those transport modes suffer from such shortcomings. 
As a result, ridesharing services in Dhaka are getting more popular. Uber, the biggest global ridesharing company, started its service in Dhaka in 2016. The huge demand for ridesharing services has influenced several similar domestic ridesharing services in Dhaka, including bike shares. Most of the existing ridesharing services in Dhaka use 4-seat private cars and provide a pick-n-drop service for individuals or a single ride at a time. Thus, it is expensive and is not an affordable choice for daily commutes to work.

Commercial ridesharing services are mainly designed for passengers from all walks of life who can afford their services. The type and nature of commuting needs of community mobility have long been starved of attention. A type of transportation to accommodate community mobility has already existed in the form of school bus, staff bus, hospital bus, etc.; however, digitization of such mobility services is yet to come.

According to the Bangladesh Telecommunication Regulatory Commission (2020), there are 101 million people (63\% of the population) using internet in Bangladesh [28]. As an alternative solution to unreliable public transport, the people of Dhaka city are shifting towards using transport services that are accessible through the use of internet. Thus, ride-hailing services are also becoming popular in Bangladesh. However, these commercial rideshare services are designed for all types of users and purposes. None of these rideshare services are specifically designed for SME employees for work travel purposes. However, with the growing trend of economic activities, more men and women are travelling for work on a regular basis, and conveying dissatisfaction regarding the existing transport system of Dhaka City. Our earlier work [18] estimated that the cost of operating a group rideshare for work would be $\$ 1$ USD per ride per person if a 10-seated-van is used to provide such a service. That would accumulate to $\$ 40$ USD cost a month for an employee to commute to work using such a service considering 20 working days in a month and two trips a day. However, it is important to find out how much the employees spend on their work commute, who meets the criteria of spending $\$ 40$ USD to use such services and what are their travel behavior to work is.

\subsection{Research Objective}

This paper aims to understand the travel behavior of corporate employees in emerging countries in order to examine the suitability of a rideshare service for them. In order to understand travel behavior, a set of questions was developed and an investigation was carried out.

\subsection{Major Research Questions}

Understanding the travel pattern of commuters is quite straight forward. The work times of almost all the employees are similar. The offices in Dhaka city start at 10:00 and end at 18:00. However, there are exceptions. People travel from different parts of the city. Employees use different modes of transports depending on the availability, comfort, and affordability.

Several research works have attempted to understand the rideshare user travel behavior and interpret this information to predict the determinants for choosing rideshare services for a commute. In a study, Alonso-Gonzalez et al. (2020) investigated the influence of fare discount, additional travel time and willingness in individuals' decision making regarding using rideshares. The authors disentangled the sharing aspect of time-cost trade off, i.e., to what extent individuals are willing to detour in order to get a discounted fare. They found the willingness to share rides primarily depended on the time-cost trade-offs [29]. In another study conducted in Ghana, it was found that young people of that region were more inclined to use a rideshare service due its convenience and cost advantages over conventional taxis [30]. Morales Sarriera et al. (2016) focused on social and behavioral for consideration of a shared ride. They found that social interaction is relevant to mode choice; the more positive a social interaction is, the more people shift to a shared ride [31], which related to feelings of comfort and safety.

Based on the studies mentioned above, the following research questions (RQs) are adapted to understand the travel behavior of the target community: 
RQ1. What are the employees' commuting distances for work?

RQ2. What primary modes of transport do they use to commute to work?

RQ3. How much time do they use for a work commute?

RQ4. What is the travel expenditure pattern?

RQ5. What are the consideration points for choosing a mode of transport?

RQ6. What is their attitude towards using rideshare services?

RQ7. Who would be the potential users of a ride-share service for a work commute?

This study aims to find the answers of the above questions by conducting a survey among SME employees who commute to work regularly to a common location or vicinity.

\section{Study Profile and Data Pre-Processing}

In this section, we describe the study profile and methods followed for pre-processing survey data.

\subsection{Study Profile}

In order to understand the travel pattern of SMEs, a survey was carried out in Dhaka city, Bangladesh. Our target population for the survey is the working community who commutes to an office daily for work. Grameen Bank Complex (Figure 1) located in Mirpur Sector-2 in the west part of Dhaka city was selected as the study area. This building complex houses 54 SME corporate offices where approximately 560 people commute daily for work, travelling from different parts of Dhaka city. The average employee size is approximately 10 people. All the SMEs were invited to participate in the survey. Out of 54 SMEs, 20 of them agreed to participate. The total number of participants is 314 . Of them, 60 were female and 254 were male. The participants belonged to different affiliations and income brackets. The study was conducted in September 2018. Figure 1 shows the location of Grammen Bank Complex in Mirpur, Dhaka City (map on the left) and the building of Grameen Bank Complex (picture on the right).

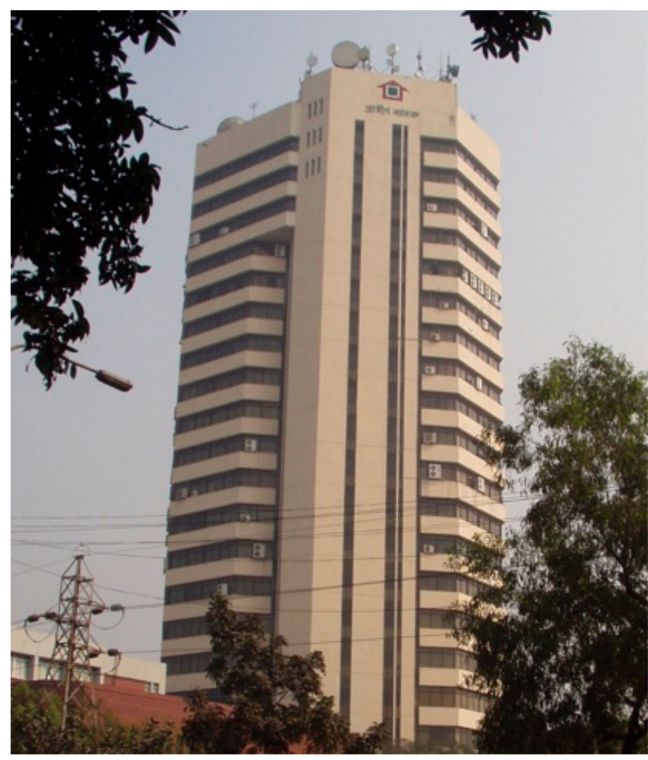

(a) Grameen Bank Complex

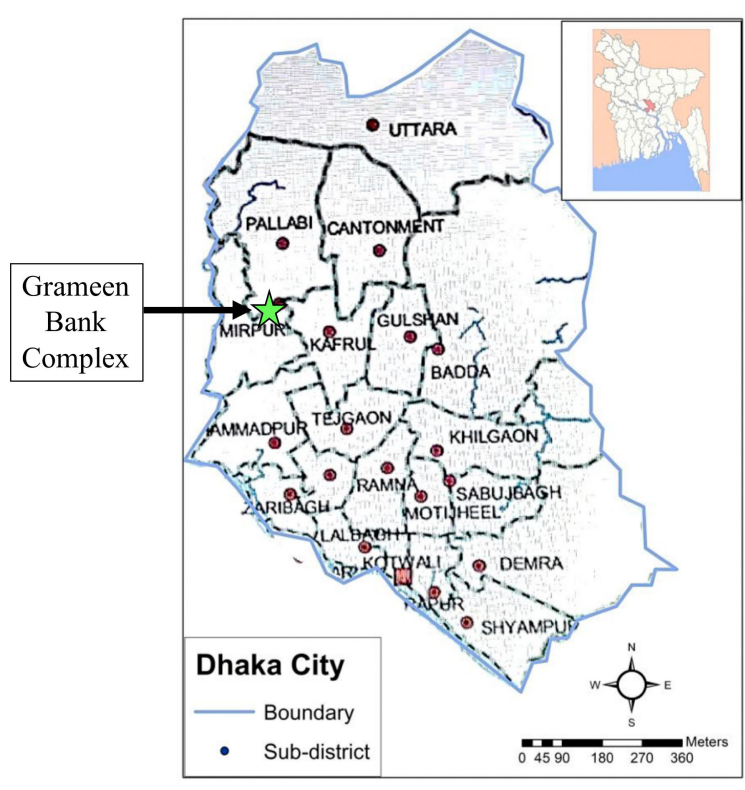

(b) Map of Dhaka City

Figure 1. (a) Grameen Bank Complex where 54 Small and Medium Enterprises (SMEs) are located, and 560 employees commute every day from different locations of Dhaka city. (b) Location of Grameen Bank Complex in Mirpur-2 that is located in west part of Dhaka city. The map is collected from [32]. 


\subsection{Survey Questionnaire}

We conducted the survey by using a questionnaire that consisted of 37 questions and was presented in the following 4 categories, which are shown in Table 1 :

Table 1. Categories of survey questionnaire and description of questions.

\begin{tabular}{cc}
\hline Category & Description of Questions \\
\hline $\begin{array}{c}\text { Category 1: Work commute } \\
\text { Category 2: Personal } \\
\text { errand commute }\end{array}$ & $\begin{array}{c}\text { 8 questions about commuting schedule, distance, duration, route, } \\
\text { zone, expenditure }\end{array}$ \\
$\begin{array}{c}\text { Category 3: Employees' attitude } \\
\text { on using rideshare services }\end{array}$ & $\begin{array}{c}10 \text { questions about their knowledge about rideshare services, } \\
\text { willingness to use, reasons for choosing or not choosing } \\
\text { pattern of travel, expenditure } \\
\text { rideshare services }\end{array}$ \\
$\begin{array}{c}\text { Category 4: Participants } \\
\text { demographic information }\end{array}$ & $\begin{array}{c}8 \text { questions about their age, gender, residential zones, boarding } \\
\text { points, occupation, affiliations }\end{array}$ \\
\hline
\end{tabular}

In this paper, findings from question categories 1 and 3 are considered.

\subsection{Pre-Processing of Survey Data}

While testing the reliability of the survey data we found some inconsistencies in the distance and commuting expense data provided by the respondents (i.e., employees of the SMEs). Pre-processing of commuting distance and expense data is presented below:

\subsubsection{Pre-Processing of Commuting Distance Data}

Respondents do not have exact measurements about the distance they travel from home to office. We found inconsistencies in their responses. Fortunately, the survey data contained the address of the nearest boarding points from where they start their journey from home to office. We derived the accurate distance data using Google Map for all of the 314 employees and used the accurate data for our analysis.

\subsubsection{Pre-Processing of the Monthly Commuting Expense Data}

Some major inconsistencies were seen in the nature of the monthly commuting expense data given by the surveyed employees (Figure 2). For example:

- Some of the employees use their own car and motorbikes for work commute. They mentioned their monthly commuting cost as $0 \mathrm{BDT}$, which is doubtful as every privately-owned vehicle incurs maintenance, fuel, tax, and parking costs. As they do not have to pay a fare, they misunderstood the concept 'cost'.

- Some employees are provided with office cars for their commute to work. They also mentioned "zero" for their transportation cost. Some of them estimated their monthly cost to own and maintain a car. Therefore, we found two polarized values even for the same travel distance.

- Similar inconsistency was seen in the data for travelling by bicycle. Some people mentioned "zero" and the rest mentioned the maintenance cost of the bicycle.

- A significant portion of the employees commute to work by walking. For many of them, walking is the primary and only mode of transport. However, some employees who commute by walking as the primary mode of transport, use a rickshaw (a three-wheeled manually driven or battery driven tricycle that can accommodate one driver and two passengers), CNG taxis (a three-wheeler-automobile that uses Compresses Natural Gas as fuel and is used for providing taxi services, which is locally called CNG), and occasionally buses, etc., as well. As a result, there is incurrence of expenses for commuting while only walking is not expected to incur any cost. Hence, the data of these employees were also inconsistent. 


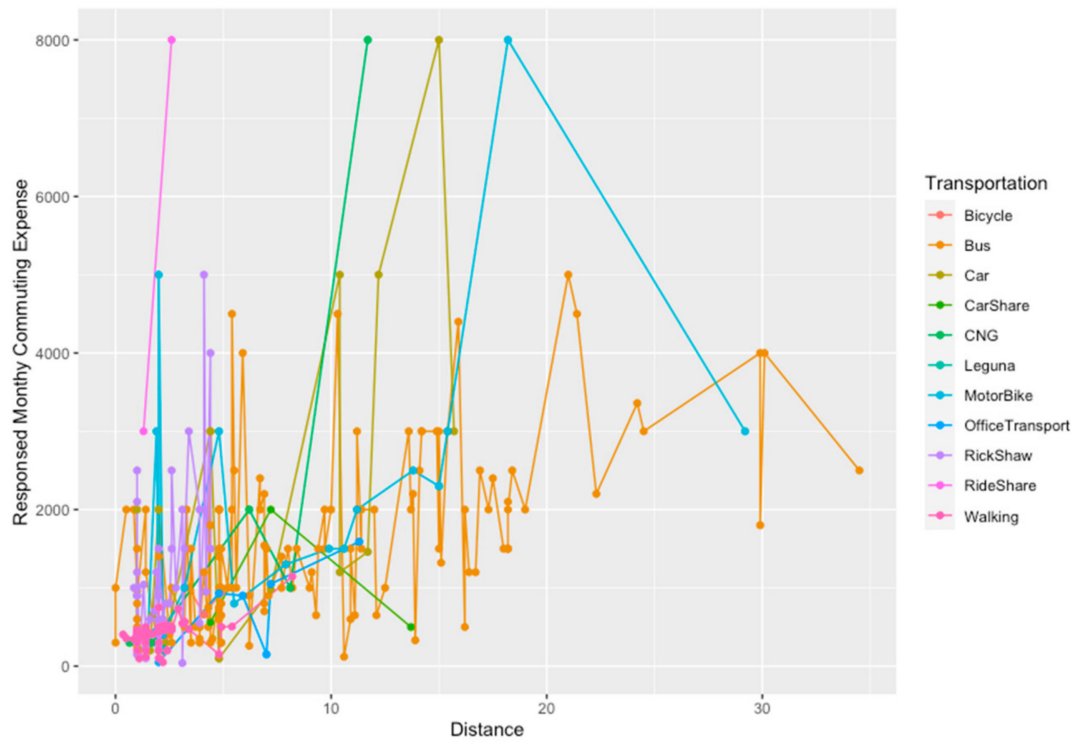

Figure 2. Inconsistencies in received monthly commuting expense data in survey response.

Due to these inconsistencies in the monthly expense data, we derived the data through the following four steps.

- We derived the cost of using an Uber rideshare service for the source and destination points for each employees' two-way journey, and calculated the monthly costs of using an Uber service for the work commute for each employee.

- We derived the ratio of each employee's monthly cost and monthly Uber cost.

- We generated the median of the ratio for each mode of primary transport.

- Each Uber cost of the surveyed employees was divided by the designated median generated for each mode of transport, and thus we derived the monthly commuting costs for the work commute.

This way, the inconsistencies of the data are minimized and consequently the accuracy of the processed data increases as shown in Figure 3. Based on the locations of all the participants, the accuracy of all the data was manually verified.

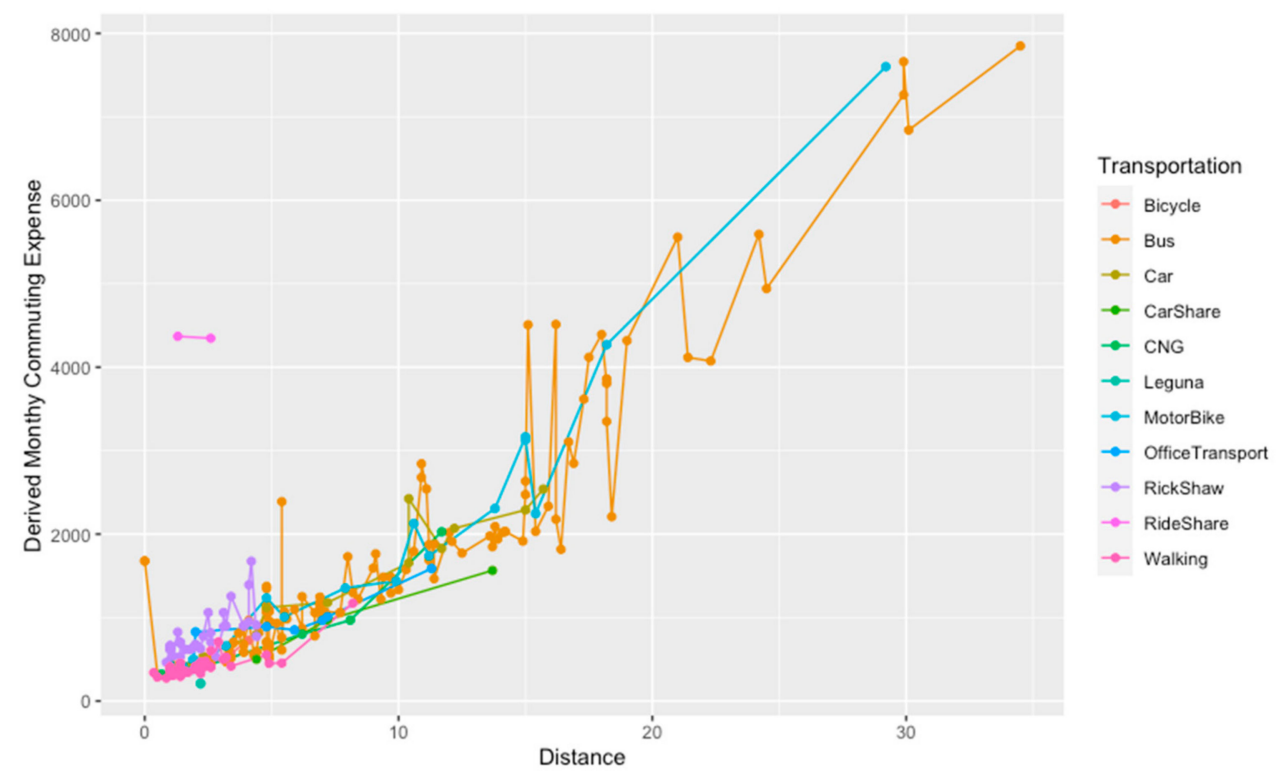

Figure 3. Monthly Expense data after data pro-processing. 


\section{Survey Findings}

We analyzed the collected data to explain the travel behavior. The observations are described as follows:

Observation\#1 The shortest distance commuted is $0.2 \mathrm{~km}$ and the longest $35 \mathrm{~km}$. Approximately $40 \%$ employees commute less than $2.5 \mathrm{~km}, 24.84 \%$ commute $2.6-5.0 \mathrm{~km}, 13 \%$ commute $5.1-10.0 \mathrm{~km}$ and $10 \%$ commute 10.1-15.0 km. (RQ1)

Figure 4 shows the distance from the office to each employee's pickup points near their residence. As Dhaka is very congested during the rush hours, employees tend to find a residence near their workplace. Therefore, it is observed that all the employees live within $0.2 \mathrm{~km}$ to $35 \mathrm{~km}$. More than $40 \%$ commute from $2.5 \mathrm{~km}$ distance, $24.84 \%$ travel within $2.6-5.0 \mathrm{~km}$ distance. Considering the culture of the Bangladeshi family, children's schools and women's workplaces are given priority to select a living place. In this figure, we can observe that all the female participants are living within a $20 \mathrm{~km}$ distance and $70 \%$ of them live within a $5 \mathrm{~km}$ distance of their workplace.

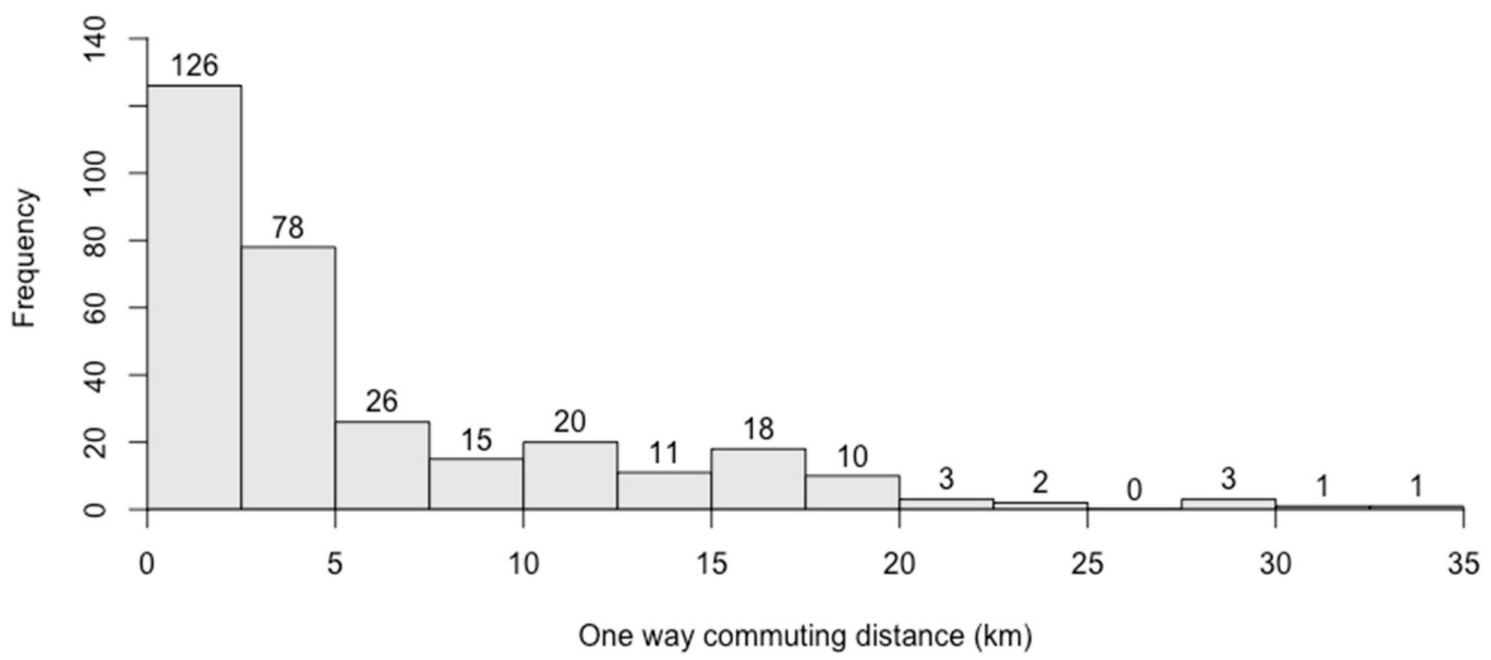

Figure 4. One-way commuting distance to work.

Considering both the genders, $13 \%$ travel within $5.1-10.0 \mathrm{~km}, 10 \%$ within $10.1-15.0 \mathrm{~km}, 8.9 \%$ within $15.1-20.0 \mathrm{~km}$. In conclusion, $47.84 \%$ participants live within a $2.6-15.0 \mathrm{~km}$ distance. This population mostly use motorized vehicles, e.g., a motorbike, bus, CNG taxi, car, etc. This finding provides the answer to RQ1.

Observation\#2: Bus, Walking and Rickshaw are the top three modes of primary transportation. (RQ2)

The participants were asked to select the most used primary transportation mode for commuting to their office. As shown in Figure 5, the three most used modes of transports are bus (43.95\%), walking $(21.34 \%)$ and rickshaw $(15.29 \%)$. Four percent $(4 \%)$ commute using their own car and another $4 \%$ using their own motorbike. The other vehicles used for commuting to work are bicycles, CNG-run taxies, carshare, Leguna (a three-wheeled light motor vehicle), and rideshare services. There is a bus stop near the office. There is no train service inside Dhaka city. Use of a bicycle to commute to office is not common as there is no separate bicycle lanes and also there is no bicycle parking in the Grameen complex. A group of participants use multiple vehicles to come to the office. During rainy seasons, people use rickshaws instead of walking. It is also overserved that $50 \%$ (31 out of 60 ) female corporates use the bus for their primary transportation to the office. 


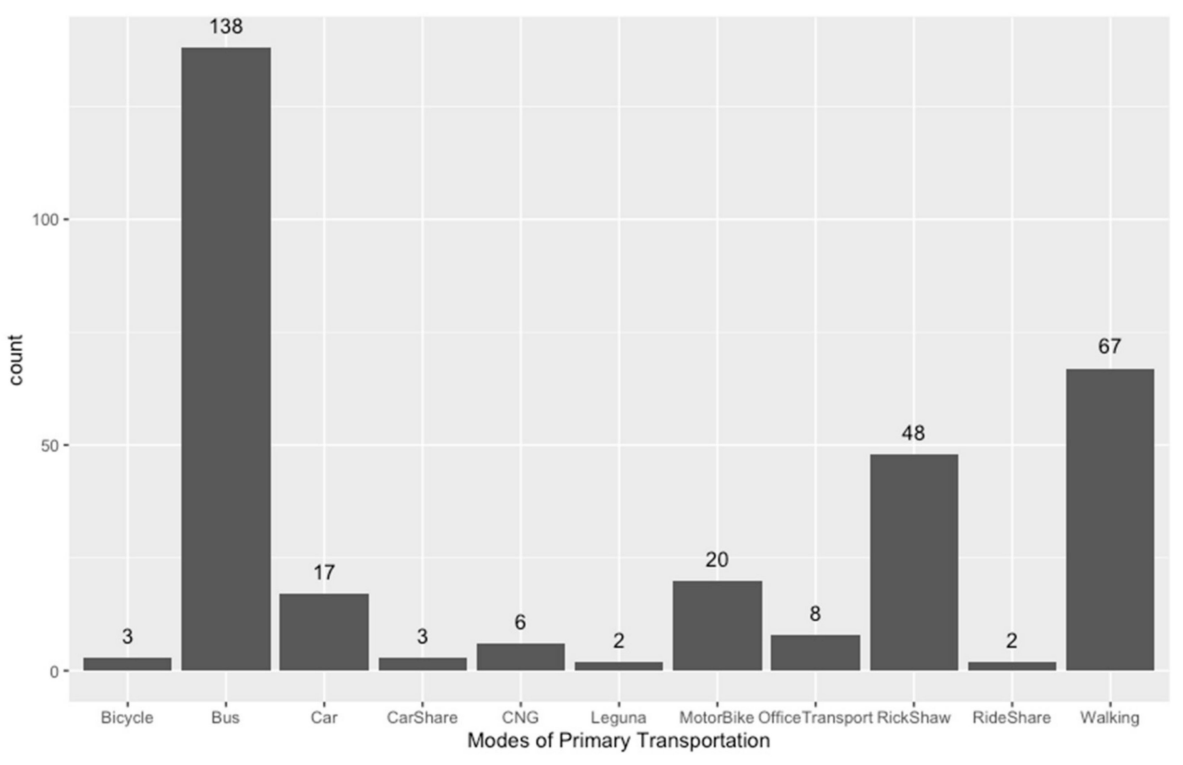

Figure 5. Modes of transportations used by SME employees $(\mathrm{N}=314)$.

While Figure 5 explained the mode of primary transports used by the employees, Figure 6 considers their distance. Employees use single or multiple number of transports to commute to the office. Each colored bar represents an interquartile range (25th to 75 th percentile) of distances travelled using each mode of transportation and the bold line inside the interquartile range indicates the median. The red dots represent the outliers.

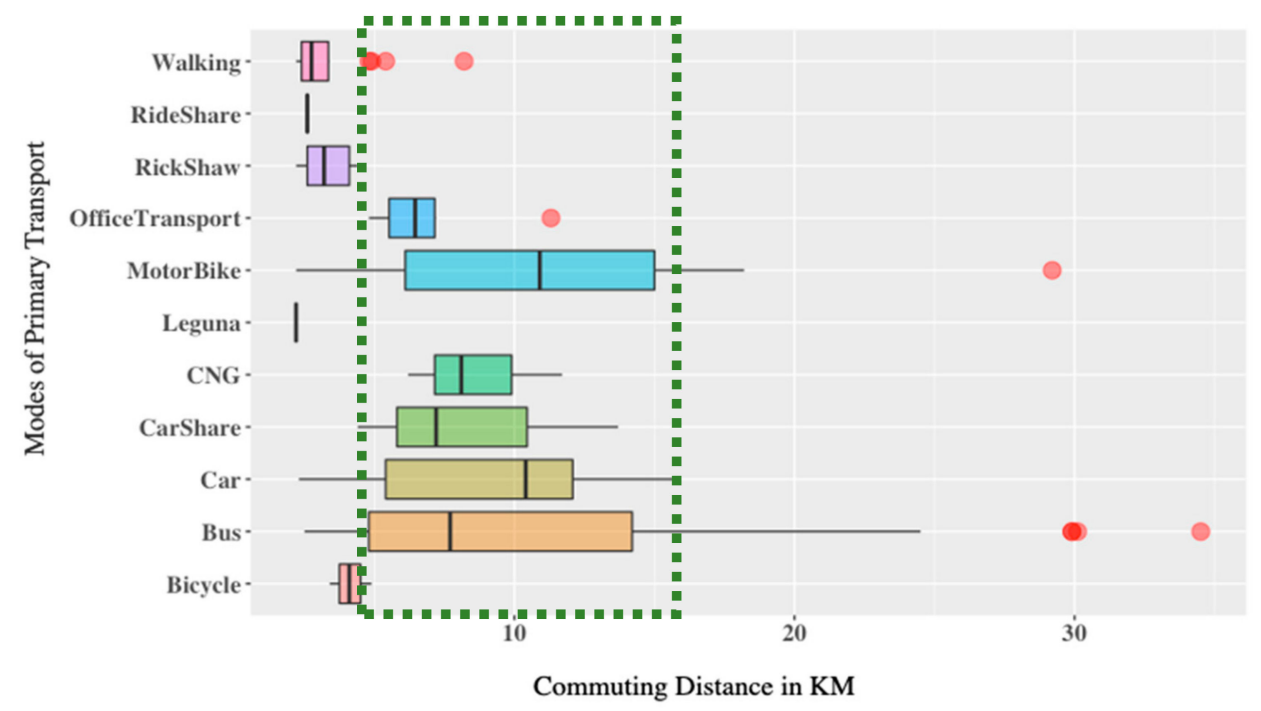

Figure 6. Commuting distance pattern by different modes of transport.

Employees living within a short distance prefer to walk or use a non-motorized vehicle, e.g., rickshaw, bicycle, etc. It is overserved that $88.54 \%$ employees live within a $15 \mathrm{~km}$ distance and, among them, $65.61 \%$ use non-motorized vehicles who live within $5 \mathrm{~km}$ distance. The rest $(88.54-65.61=22.93 \%)$ of the employees use public transport (where they are victims of sexual harassments and environmental pollution) and private cars or bikes. These employees could be potential users of rideshare services to save time and increase comfort. These findings provide answers to RQ2.

Observation\#3: Travel duration for $94 \%$ people is within $60 \mathrm{~min}$. (RQ3) 
The duration of one-way travel to work for the majority of the employees ( 295 people, $94 \%$ ) is within $60 \mathrm{~min}$. Employees who reach their workplace within $20 \mathrm{~min}$ constitute $16.56 \%$ of the test group (52 people). These are the group of people who mostly walk or take a rickshaw to work. The 2nd largest group is people who travels for $30 \mathrm{~min}$ to work (55 people, 17.52\%). One fifth of the population travels for 30 to $60 \mathrm{~min}$ to work (62 people, 19.68\%). Participants who travel more than $60 \mathrm{~min}$ constitute approximately $5 \%$ of the participant population. Figure 7 shows the frequencies for different commuting durations. It is overserved that $50 \%$ (30 out of 60) of female participants travel for $30 \mathrm{~min}$. Observation 3 provides the answer to RQ3.

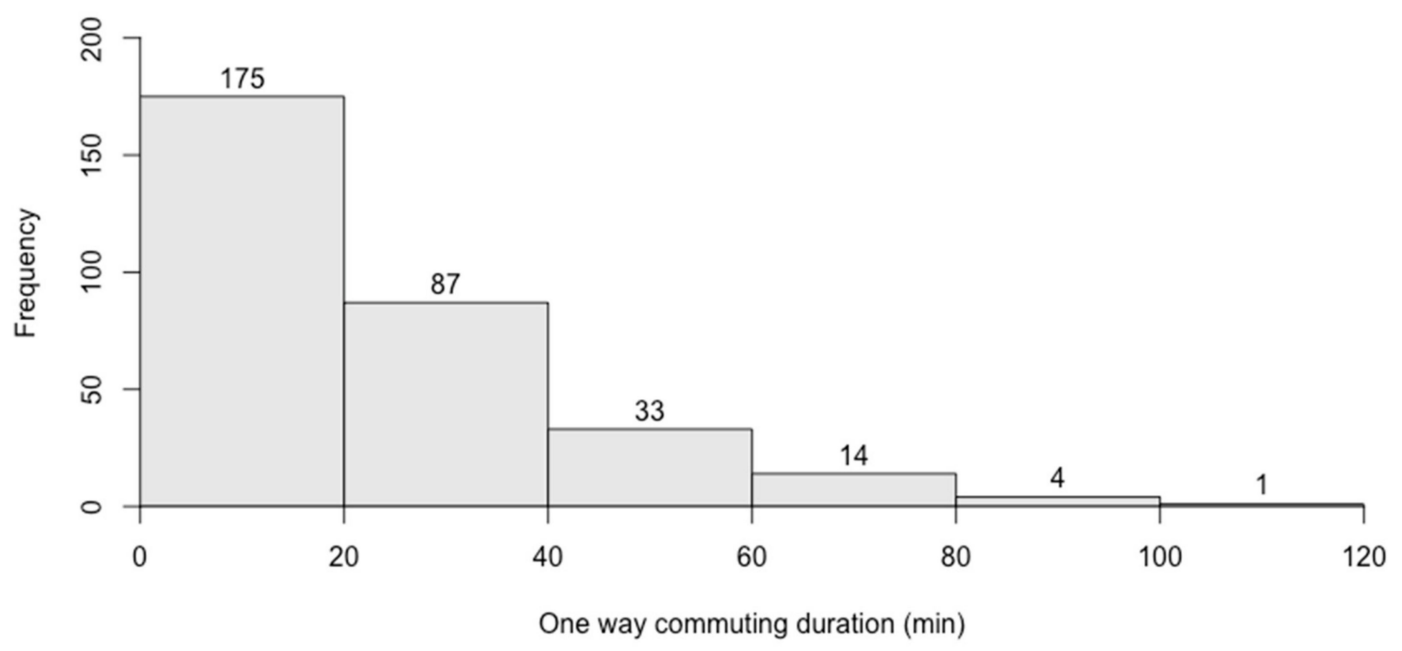

Figure 7. One way commuting duration and their frequencies $(\mathrm{N}=314)$.

Observation\#4: 62.7\% of employees spend up to 1000 BDT, 21.02\% spend 1001-2000 BDT and 7.64\% spend 2001-3000 BDT per month for their work commute. (RQ4)

Figure 8 illustrates these findings. The employees were asked about monthly expenditure of work travel. The largest group (32.8\%, 103 people) spends less than 500 BDT which is equivalent to $\$ 6.25$ USD. The second largest group (29.94\%, 94 people) spends within 501-1000 BDT (\$6.25-12.5 USD). These two groups represent more than half of the employees $(32.8+29.9=62.7 \%)$ among the total number of participants. The next largest group consists of 43 people (13.69\%) who spend within 1001-1500 BDT (\$12.5-18.75 USD). Twenty-three employees (7.32\%) spend 1501 2000 BDT (\$18.75-25 USD). Twenty-four employees (7.64\%) spend 2001 3000 BDT (\$25 37.5 USD). Nine employees (2.87\%) spend 3001-4000 BDT (\$37.5-50 USD), 11 employees (3.5\%) spend 4001-5000 BDT (equivalent to \$50-62.5 USD), and the remaining 7 employees (2.22\%) spend more than 5000 BDT (\$62.5 USD) to 8000 BDT (\$100 USD).

Figure 9 shows the range of spending for each mode of primary transport used by the employees in boxplots. Each colored bar represents interquartile range (25th percentile to 75 th percentile) of monthly commuting expenses for each mode of transportation and the bold line inside the interquartile range indicates the median. The red dots represent the outliers. The green dotted box inside Figure 9 indicates the common range of expenses (500-4200 BDT, equivalent to $\$ 6.25-52.5$ USD) made by employees for using motorized modes of transportation. However, Figure 9 shows that Leguna and rideshare services are outside of that range. Motorbike, bus, and car have the widest range of commuting expenses. Public bus fare is cheap, but private AC buses are expensive. Observation\#4 answers RQ4.

Observation\#5: Travel time, safety and expense are the main considerations while choosing a mode of transport. (RQ5) 


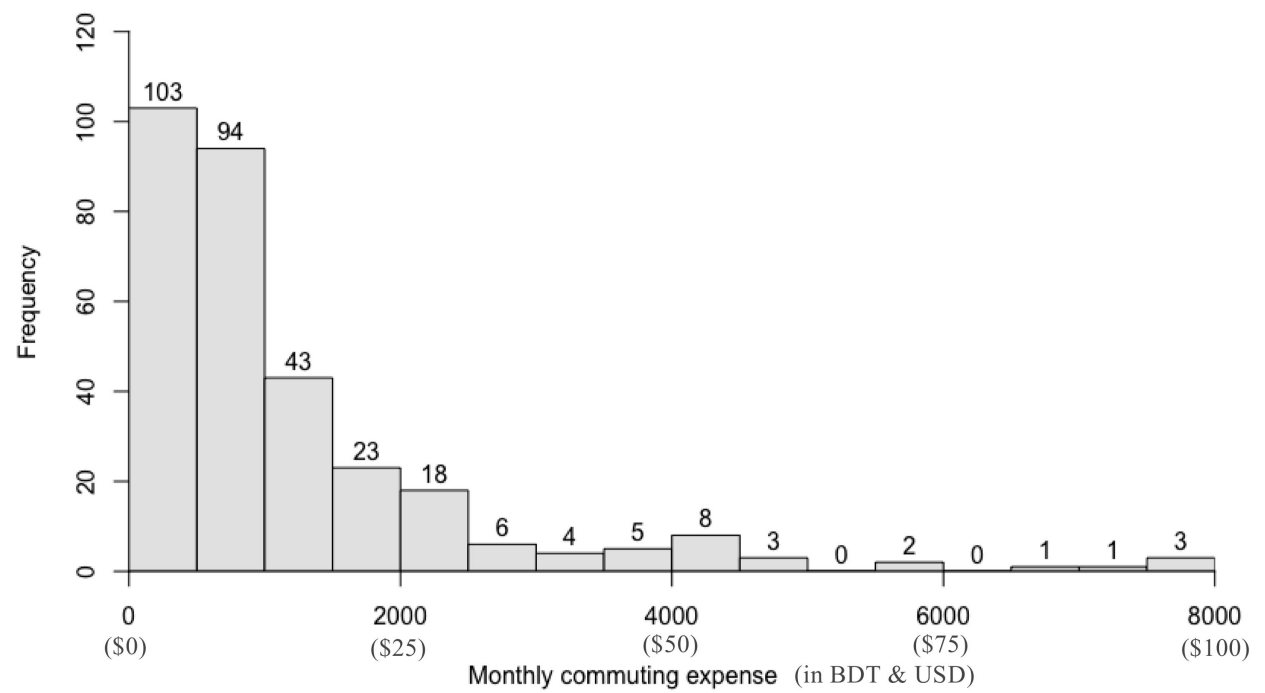

Figure 8. SME employees' pattern of work commute expenditure per month $(\mathrm{N}=314)$ in BDT and USD.

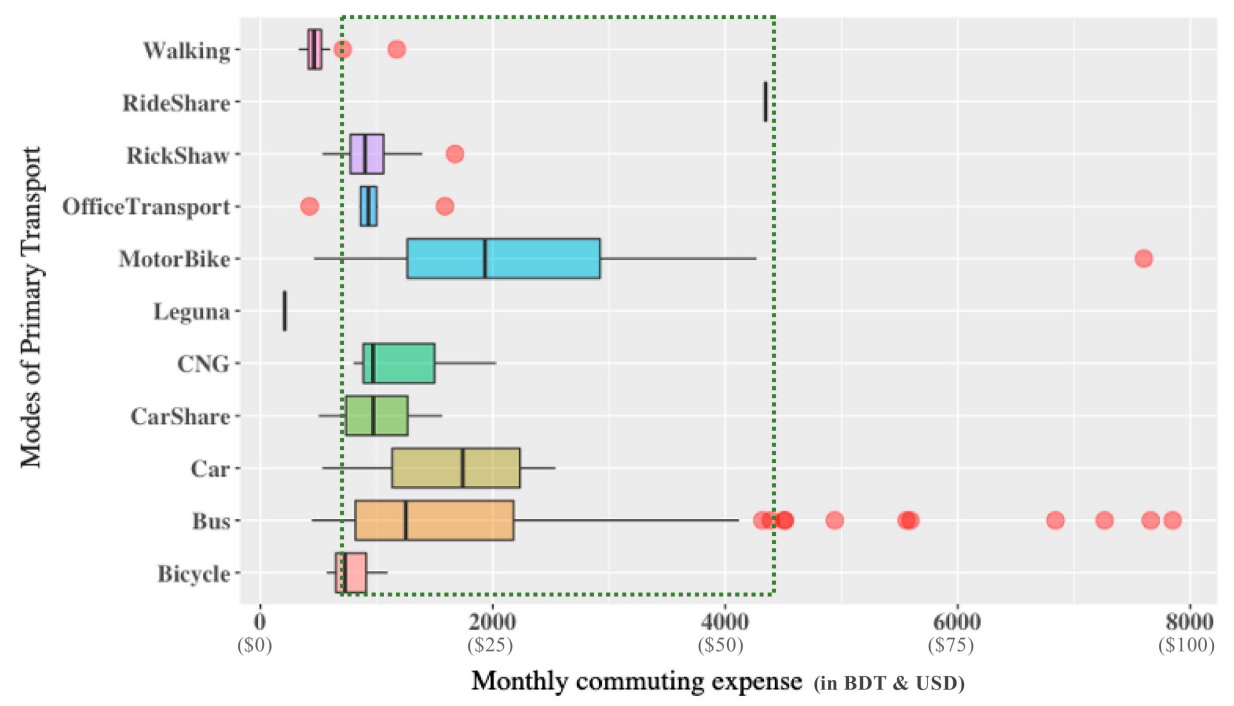

Figure 9. The ranges of monthly travel expense for each mode of transport used by the participants.

The participants were asked to rank the factors they take into consideration when choosing a mode of transport to commute to their workplace. The topmost factor for choosing a mode of transport is travel time followed by travel safety and cost. They also give importance to travel convenience and effect on health while choosing a mode of transport. Figure 10 shows this finding. Observation\#5 provides answers for RQ5.

Observation\#6: One third of the participants would like to use a rideshare service for their work commute. (RQ6)

Participants were asked if they would use a rideshare service for work. Approximately one third of the participants (102 people, $32.38 \%$ ) responded positively (Figure 11). Approximately $56 \%$ of these participants use bus, $7 \%$ car, and $4 \%$ motorbike. Approximately one-fourth of the participants who responded positively belong to the non-motorized vehicle user group and travel less than $3 \mathrm{~km}$ to work.

On the other hand, half of the participants $(49.48 \%, 157$ people) responded negatively, among whom approximately $30 \%$ travel by bus, $32 \%$ by walking, and $19 \%$ by rickshaw. However, $16 \%$ of the participants said they might use rideshare services and from that group 59\% travel by bus. This finding provides an answer to RQ6. 


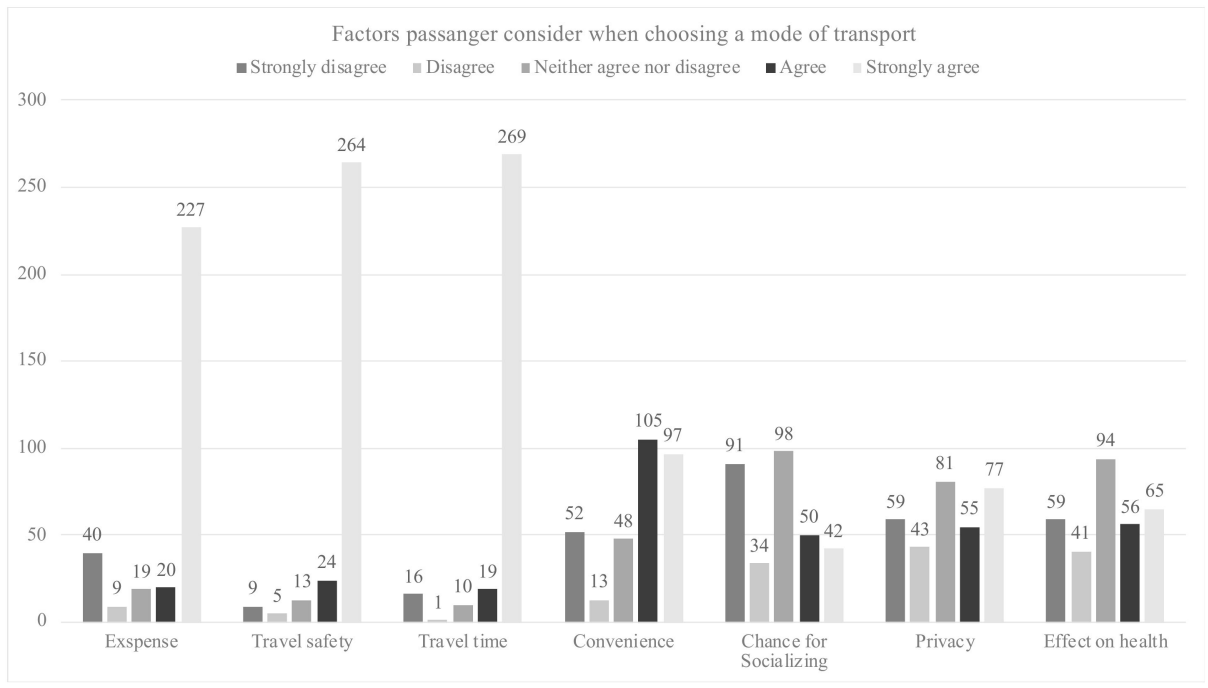

Figure 10. Factors considered on importance scale when choosing a mode of transport by SME employees.

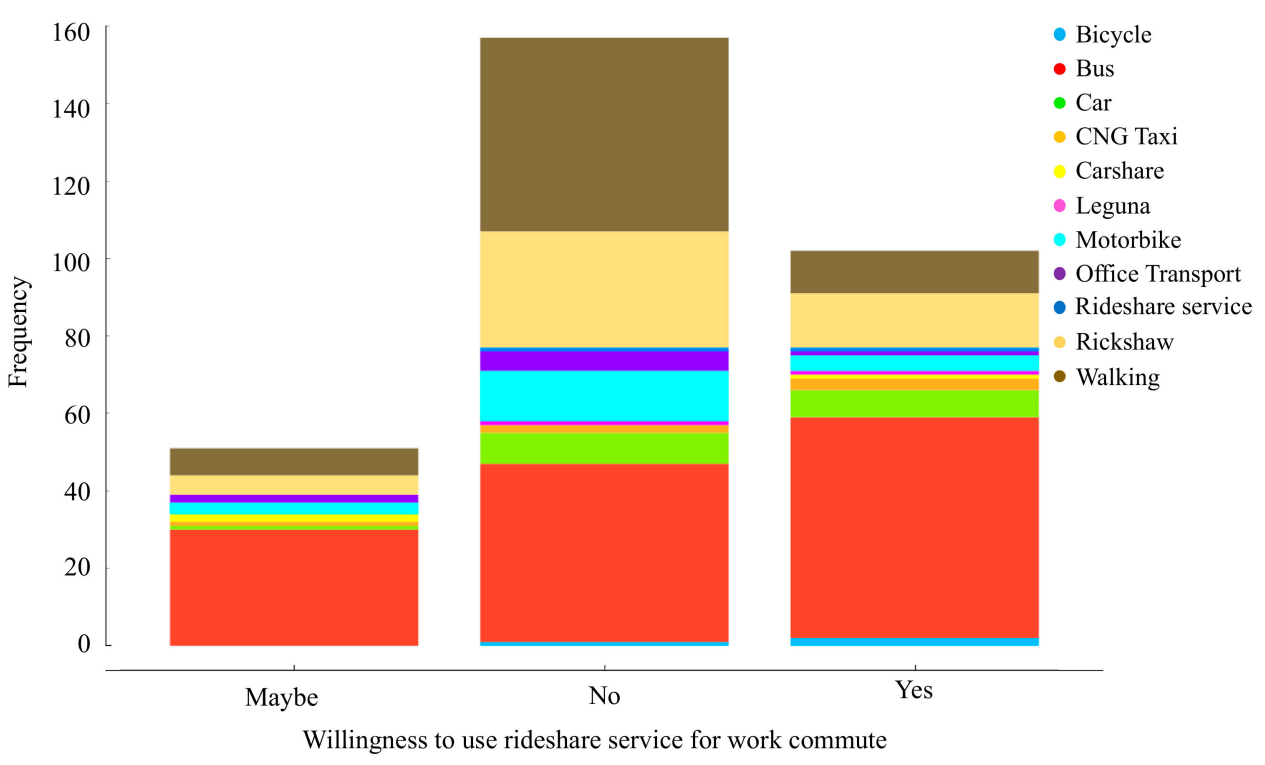

Figure 11. SME employees' willingness to use a rideshare to work and modes of transportation used by them in each response segment.

\section{Discussion}

In this study, travel patterns of 314 employees working in the same office building were observed. It was observed that bus (43\%), walking $(22 \%)$, and rickshaw $(16 \%)$ are the three major transportation modes. Approximately $40 \%$ percent of employees live within a $2.5 \mathrm{~km}$ distance, the shortest commuting distance is $0.2 \mathrm{~km}$ and the longest commuting distance is $35 \mathrm{~km}$. Employees reaching their workplace within 60 min of travel is $94 \%$ and approximately $62 \%$ of the employees spend up to \$12.5 USD for their work commute in a month.

Depending on the type of vehicle (motorized or not), the participants can be classified into two groups (1) Non-motorized vehicle users (walking, rickshaw, bicycle), (2) Motorized vehicle users (bus, car, CNG-run taxi, carshare, Leguna, motorbike, office transport, rideshare). The characteristics of these two groups have similarities as well as differences which are presented in Table 2. 
Table 2. Characteristics of motorized and non-motorized vehicle users. (RQ1,2,3,4).

\begin{tabular}{|c|c|c|}
\hline Category & Non-Motorized Vehicle Users & Motorized Vehicle Users \\
\hline Distance & $\begin{array}{l}\text { Usually travels within } 0.1-2.5 \mathrm{~km} \\
\text { (except for bicycles commuting } \\
3-5 \mathrm{~km} \text { ) }\end{array}$ & $\begin{array}{l}\text { Usually travels more than } 2.5 \mathrm{~km} \\
\text { (except for some bus users commuting } \\
\text { less than } 2.5 \mathrm{~km} \text { ) }\end{array}$ \\
\hline Travel Duration & Mostly within $20 \mathrm{~min}$ & $\begin{array}{l}\text { Miscellaneous, within a range of } \\
20-100 \mathrm{~min}\end{array}$ \\
\hline Commuting expense & Ranges from \$0-12.5 USD & Ranges from \$10-100 USD \\
\hline
\end{tabular}

RQ6 of this study seeks to find who could be the potential user of a group rideshare commute to work. From the findings, it is observed that $32 \%$ of the employees surveyed responded positively towards using a rideshare service for work, and another $18 \%$ said they might use a such a service. However, half of them said they are not willing to use a rideshare service for their work commute. Potentiality of an employee as a rideshare user can also be indicated by their pattern of work commute. For example, employees who live within a short distance or use their own cars or have a direct bus connection have less potential to become a user of this type of service. Table 3 discusses the criteria of non-potential users of a rideshare service for their work commute.

Table 3. Non-potential users of a ride-share service for their work commute (RQ6).

\begin{tabular}{|c|c|c|}
\hline Category & Non-Potential Rideshare User & Reason \\
\hline Transport Mode & $\begin{array}{l}\text { Employees who come to office on } \\
\text { foot }(22 \%)\end{array}$ & $\begin{array}{l}\text { Motorized vehicle is not a requirement for } \\
\text { their work commute }\end{array}$ \\
\hline Travel Duration & $\begin{array}{l}\text { People who arrive at the office } \\
\text { within } 10 \mathrm{~min}\end{array}$ & $\begin{array}{l}\text { Service would be designed to } \\
\text { accommodate optimum passengers from } \\
\text { an optimum furthest distance }\end{array}$ \\
\hline Commuting Expense & $\begin{array}{l}\text { Employees who spend no money } \\
\text { or less than } \$ 40 \text { USD a month for } \\
\text { their work commute. }\end{array}$ & $\begin{array}{l}\text { The operating cost required for providing } \\
\text { this service would require more than } \\
\$ 40 \text { USD a month per passenger [7] }\end{array}$ \\
\hline Commuting Distance & $\begin{array}{l}\text { Passengers living within } 2.5 \mathrm{~km} \\
\text { distance from the office }\end{array}$ & $\begin{array}{l}\text { Optimum efficiency of service would } \\
\text { require optimum passengers from the } \\
\text { optimum farthest distance }\end{array}$ \\
\hline
\end{tabular}

In contrast $28 \%$ of the bus users live within a $3.1-5 \mathrm{~km}, 20 \% 5.1-10 \mathrm{~km}, 13 \% 10.1-15 \mathrm{~km}$ and $12 \% 15.1-20 \mathrm{~km}$ distance of their workplace. These groups represent $33 \%$ of the total surveyed population. Another $2.54 \%$ of participants ( 8 people) travel by car and $3.8 \%$ of participants by motorbike for a distance of $3.1 \sim 20 \mathrm{~km}$. Among the other modes used for traveling more than $3 \mathrm{~km}$ are CNG-run taxis, car-share services and office transport. These groups could be potential users for ride-share services. Table 4 presents the potentials users of ride share services along with the reasoning of these users to use such services.

Only two of the 314 participants meet both the affordability and distance criteria of being a potential user of rideshare service to work. However, it is difficult to understand from this study if they would be open or flexible for a time-compromise window. Also, it is difficult to understand from the findings if such a rideshare would bring them a time benefit.

There are 29 participants who responded "Maybe" and meet the distance criteria. However, their current average travel expense is 1.5 times cheaper than the required expenses of becoming a potential user. If participants take only the financial aspect into consideration, their possibility to use a rideshare service seems to be negative.

The top three important factors that SME employees take in consideration for choosing a mode of transport for work commute are travel time, travel safety, and travel expense. More employees might be interested using a rideshare service for their work commute if they find more time and safety benefits from using such service. Hence, evidence showing time and travel safety benefits for users are 
needed to predict the possibility of how many participants might actually use the rideshare service for commuting to work if offered.

Table 4. Potential users of a ride-share service for work commute (RQ6).

\begin{tabular}{|c|c|c|}
\hline Category & Potential Rideshare User & Reason \\
\hline Transport Mode & $\begin{array}{c}\text { Employees who commute more } \\
\text { than } 2.5 \mathrm{~km}\end{array}$ & $\begin{array}{l}\text { Motorized vehicle is a requirement for } \\
\text { their work commute }\end{array}$ \\
\hline Travel Duration & $\begin{array}{l}\text { People who can save time and } \\
\text { who are flexible to compromise } \\
\text { time-window }\end{array}$ & $\begin{array}{l}\text { Service would be designed to } \\
\text { accommodate optimum passengers from } \\
\text { an optimum furthest distance }\end{array}$ \\
\hline Commuting Expense & $\begin{array}{l}\text { Employees who can spend more } \\
\text { than } \$ 40 \text { USD a month on their } \\
\text { work commute. }\end{array}$ & $\begin{array}{l}\text { The operating cost incurring for } \\
\text { providing this service would require more } \\
\text { than } \$ 40 \text { USD a month per passenger [7] }\end{array}$ \\
\hline Commuting Distance & $\begin{array}{l}\text { Passengers living within a } \\
2.5-15 \mathrm{~km} \text { distance from office }\end{array}$ & $\begin{array}{l}\text { Optimum participants living below } \\
2.5 \mathrm{~km} \text { mostly use non-motorized mode of } \\
\text { transport to for work commute. Optimum } \\
\text { efficiency of service would require the } \\
\text { optimum passenger from the optimum } \\
\text { farthest distance }\end{array}$ \\
\hline
\end{tabular}

It is assumed that corporate ride share service will be safer for the corporates, especially for female corporates. Rideshare services will be provided only to registered members. Therefore, it would be easily tracked in the case of any harassment. Other safety issues like theft and robbery inside the fleet is very unusual. The rideshare car driver is a proper licensed person, provided with corporate guidelines on driving safety and fewer accidents are expected to occur than on public transport.

\section{Conclusions}

This paper investigated the travel patterns of 314 SME employees to design a financially viable ridesharing service for them. It reports their travel behavior in terms of the mode of transports, distance, and travel expense pattern. It also investigated their attitude towards using a rideshare service for their work commute. Based on the findings on their travel attributes, this paper recommends a set of criteria and classifies the potential and non-potential users of a rideshare service to the workplace. We recommend that employees living within a distance of $2.5-15 \mathrm{~km}$, currently using motorized vehicle for work commute, who can spend $\$ 40$ USD a month and agree to a mutually determined commuting schedule are the users with the most potential for an effective and financially sustainable rideshare service. These findings can be used by commercial private transport providers for designing a work commuter "pickup and drop-off" service. In addition, joint-transport initiatives can be formed among a group of SMEs who are enthusiastic about providing a safer and more affordable work commute for their employees.

The same methodology can be used to design rideshare services for school children and college or university students. We are working on scheduling the rideshare service to estimate the pickup time and pick up points for each passenger. This model targets SMEs in the same vicinity. We assume that the working time for all the SMEs are the same, which is a hard assumption. People with different working times will require multiple vehicles. Scheduling for them will be a challenge both financially, technically, and socially.

Author Contributions: Conceptualization, methodology, survey design, data curation, writing—original draft preparation is done by N.A. and A.A. Data collection is conducted M.M.R. Review and editing is done by K.H. and M.I.H. All authors have read and agreed to the published version of the manuscript.

Funding: This research was partially funded by Toyota Motor Corporation during three party joint research project among Toyota Motor Corporation, Grameen Communications and Kyushu University in 2018.

Acknowledgments: The authors would like to thank Grameen Communications and all the companies who participated conducting this survey. 
Conflicts of Interest: The authors declare no conflict of interest.

\section{References}

1. Polat, C. The Demand Determinants for Urban Public Transport Services: A Review of the Literature. J. Appl. Sci. 2012, 12, 1211-1231. [CrossRef]

2. White Paper, MaaS Alliance. Available online: https://maas-alliance.eu/wp-content/uploads/sites/7/2017/09/ MaaS-WhitePaper_final_040917-2.pdf (accessed on 4 September 2017).

3. Zegras, P.C.; Eros, E.; Butts, K.; Resor, E.; Kennedy, S.; Ching, A.; Mamun, M. Tracing a Path to knowledge? Indicative User Impacts of Introducing a Public Transport Map in Dhaka, Bangladesh. Camb. J. Reg. Econ. Soc. 2015, 8, 113-129. [CrossRef]

4. Falconer, R.; Zhou, T.; Felder, M. Mobility-as-a-Service: The Value Proposition for the Public and Our Urban Systems. A White paper by ARUP MaRS 2018. Available online: https://www.marsdd.com/wp-content/ uploads/2018/04/Mobility-as-a-Service-the-value-proposition-Mar18.pdf (accessed on 20 October 2020).

5. $\quad$ Eckert, R.D.; Hilton, G.W. The Jitneys. J. Law Econ. 1972, 15, 293-325. [CrossRef]

6. Brake, J.; Mulley, C.; Nelson, J.D.; Wright, S. Key lessons learned from recent experience with flexible transport services. Transp. Policy 2007, 14, 458-466. [CrossRef]

7. Chan, N.D.; Shaheen, S. Ridesharing in North America: Past, Present, and Future. Transp. Rev. 2012, 32, 93-112. [CrossRef]

8. Okun, P. Beyond Uber: Your Guide to Ridesharing Apps around the World; CNBC: Englewood Cliffs, NJ, USA, 2019; Available online: https://www.cnbc.com/2019/11/08/top-ride-sharing-apps-in-europe-asia-south-americaafrica-and-usa.html (accessed on 20 October 2020).

9. Rayle, L.; Shaheen, S.; Chan, N.D.; Dai, D.; Cervero, R. App-Based, On-Demand Ride Services: Comparing Taxi and Ridesourcing Trips and User Characteristics in San Francisco. In Proceedings of the Transportation Research Board Annual Meeting, Transportation Research Board, Washington, DC, USA, 11-15 January 2015.

10. Li, Z.; Hong, Y.; Zhang, Z. An empirical analysis of on-demand ride-sharing and traffic congestion. In Proceedings of the 2016 International Conference on Information Systems, Dublin, Ireland, 11-14 December 2016.

11. Altshuler, T.; Altshuler, Y.; Katoshevski, R.; Shiftan, Y. Modeling and prediction of ride-sharing utilization dynamics. J. Adv. Transp. 2019, 2019, 6125798. [CrossRef]

12. Vanderschuren, M.; Baufeldt, J. Ride-sharing: A potential means to increase the quality and availability of motorized trips while discouraging private motor ownership in developing cities? Res. Transp. Econ. 2018, 69, 607-614. [CrossRef]

13. Forbes. Hussain Elius. 2020. Available online: https://www.forbes.com/profile/hussain-elius/?sh= 6ffbd0a42cb2 (accessed on 15 September 2020).

14. Akter, N.; Rahman, F.N.; Hossain, M.I. Transforming Ride-Sharing into Sustainable Business. The Daily Star. 29 October 2019. Available online: https://www.thedailystar.net/business/news/transforming-ride-sharingsustainable-business-1820065 (accessed on 15 September 2020).

15. Javid, A.; Javed, A.; Kohda, Y. Exploring the role of boundary spanning towards service ecosystem expansion: A case of Careem in Pakistan. Sustainability 2019, 11, 3996. [CrossRef]

16. Box, S.; Lopez-Gonzalez, J. The Future of Technology: Opportunities for ASEAN in the Digital Economy. In Global Megatrends: Implications for the ASEAN Economic Community; ASEAN Secretariat: Jakarta, Indonesia, 2017; pp. 37-60.

17. Abedin, N.; Kamau, J.; Kitaoka, H.; Okajima, H.; Okada, M.; Fukuda, A.; Ahmed, A. Providing safe and affordable transportation to reduce female students dropout: A case study on college girls in rural Bangladesh. In Proceedings of the 2016 IEEE International Conference on Systems, Man, and Cybernetics, SMC 2016, Budapest, Hungary, 9-12 October 2016; Institute of Electrical and Electronics Engineers Inc.: Piscataway, NJ, USA, 2016; pp. 4130-4134. [CrossRef]

18. Abedin, N.; Hisazumi, K.; Ahmed, A. Affordable Rideshare Service for Female Urban Corporates in Developing Countries: A Case Study in Dhaka, Bangladesh. In HCI International 2019_Late Breaking Posters. HCII 2019. Communications in Computer and Information Science; Stephanidis, C., Antona, M., Eds.; Springer: Cham, Switzerland, 2019; Volume 1088. [CrossRef] 
19. City Mayors. The Largest Cities in the World-Ranked 1 to 150. 2018. Available online: http://www. citymayors.com/statistics/largest-cities-population-125.html (accessed on 12 February 2019).

20. Olsson, L.; Thynell, M. Bangladesh Road and Transport Corporation Bus Project in Dhaka; Swedish International Development Cooperation Agency, Department of Infrastructure and Economic Cooperation: Stockholm, Sweden, 2004.

21. Poole, A. How-To Notes: Political Economy Assessment at Sector and Project Levels; World Bank, Public Sector and Governance Group: Washington, DC, USA, 2011; Available online: http://gsdrc.org/docs/open/pe1.pdf (accessed on 12 February 2019).

22. World Bank. Operationalizing Political Economy: Urban Bus Operations in Dhaka. South Asia Political Economy and Governance Issue Note No. 1. Available online: http://documents.worldbank.org/curated/pt/ 797631467998806501/pdf/693780BRI0P1080Bus0Operations0final.pdf (accessed on 20 September 2020).

23. Mannan, M.; Karim, M. Road Accidents in Metropolitan Dhaka, Bangladesh. IATSS Res. 1999, 2, 90-98.

24. Katz, D.; Rahman, M. Levels of Overcrowding in Bus System of Dhaka, Bangladesh. Transp. Res. Rec. 2010, 2143, 85-91. [CrossRef]

25. Rahman, S.; Nahrin, K. Bus Services in Dhaka City-Users' Experience and Opinions. J. Bangladesh Inst. Plan. 2012, 5, 93-105.

26. Shefali, K.M. Study on Gender Dimension in Dhaka Urban Transport Project; Women Development Center: Dhaka, Bangladesh, 2000; Available online: http://siteresources.worldbank.org/INTGENDERTRANSPORT/ Resources/bangurbantransport.pdf (accessed on 25 September 2018).

27. Abedin, N.; Kamau, J.; Hossain, M.I.; Maruf, R.I.; Fukuda, A.; Ahmed, A. A case study to design a mobility as a service model for urban female corporates to improve their work performance. In Proceedings of the 2017 IEEE Region 10 Conference, Penang, Malaysia, 5-9 November 2017; pp. 1445-1450.

28. Internet User Information of Bangladesh Derived from Bangladesh Telecommunication Regulatory Commission. Available online: http://www.btrc.gov.bd/content/internet-subscribers-bangladesh-april-2020 (accessed on 29 October 2020).

29. Alonso-González, M.J.; Cats, O.; van Oort, N.; Hoogendoorn-Lanser, S.; Hoogendoorn, S. What are the determinants of the willingness to share rides in pooled on-demand services? Transportation 2020, 1-33. [CrossRef]

30. Dzisi, E.K.; Ackaah, W.; Aprimah, B.A.; Adjei, E. Understanding demographics of ride-sourcing and the factors that underlies its use among young people. Sci. Afr. 2020, 7, e00288.

31. Sarriera, J.M.; Álvarez, G.E.; Blynn, K.; Alesbury, A.; Scully, T.; Zhao, J. To Share or Not to Share: Investigating the Social Aspects of Dynamic Ridesharing. Transp. Res. Rec. 2017, 2605, 109-117. [CrossRef]

32. Hough, M. Cities and Natural Process; Rutledge: London, UK, 2004; pp. 64-65. ISBN 0-415-29855-5.

Publisher's Note: MDPI stays neutral with regard to jurisdictional claims in published maps and institutional affiliations.

(C) 2020 by the authors. Licensee MDPI, Basel, Switzerland. This article is an open access article distributed under the terms and conditions of the Creative Commons Attribution (CC BY) license (http://creativecommons.org/licenses/by/4.0/). 